\title{
Influence of cereal harvest on adrenocortical activity in European hares (Lepus europaeus)
}

\author{
Nicolas Cybulska ${ }^{1}$ (D) $\cdot$ Klaus Hackländer $^{1} \cdot$ Rupert Palme $^{2} \cdot$ Alfred Frey-Roos $^{1} \cdot$ Stéphanie C. Schai-Braun $^{1}$
}

Received: 9 February 2020 / Revised: 30 September 2020 / Accepted: 5 October 2020 / Published online: 3 November 2020

(C) The Author(s) 2020

\begin{abstract}
Anthropogenic disturbances, such as habitat modifications and machines, are associated with increased levels of faecal glucocorticoid metabolites (fGCMs) in mammals, an indicator of a stress response. One human-caused process provoking incisive habitat alterations is harvesting arable crops. We investigated the effect of cereal harvest on fGCM concentrations in European hares (Lepus europaeus) in arable landscapes in lower Austria during the year 2018 by collecting 591 faecal samples before, during and after cereal harvest. fGCMs were analysed using an enzyme immunoassay, and data were analysed using linear mixed-effects models. We found that neither cereal harvest nor farming practice (organic vs. conventional) caused an overall increase in the hares' stress level. Lower vegetation density and higher proportions of bare ground were negatively correlated with fGCM concentrations, whereas the proportion of stubble fields was significantly positively correlated with fGCM concentrations in European hares. A change to more open landscapes might decrease time spent avoiding predation, and fallen grains may provide a beneficial additional food source for the hares. This indicates that European hares are well adapted to an opening up of the landscape and short-term disturbances such as cereal harvesting. In conclusion, cereal harvest had no large impact on European hares' adrenocortical activity in an arable landscape with small average field size and enough available non-farmed areas.
\end{abstract}

Keywords Brown hare $\cdot$ Lagomorpha $\cdot$ Non-invasive $\cdot$ Habitat change $\cdot$ Vegetation structure $\cdot$ Agricultural management system

\section{Introduction}

Increasing evidence and documented examples suggest that disturbances and habitat alteration as a result of human activity can act as stressors in different mammals (Navarro-Castilla et al. 2013; Rehnus et al. 2014; Lunde et al. 2016; Zbyryt et al. 2018) and birds (Thiel et al. 2008; Casas et al. 2016). The agricultural intensification has caused habitat alterations due to the loss of heterogeneity in agricultural habitats (Benton et al. 2003) and significantly changed harvesting methods by

Nicolas Cybulska

nicolas.cybulska@yahoo.com

1 Institute of Wildlife Biology and Game Management, University of Natural Resources and Life Sciences, Vienna, Gregor Mendel-Str. 33, 1180 Vienna, Austria

2 Unit of Physiology, Pathophysiology and Experimental Endocrinology, Department of Biomedical Sciences, University of Veterinary Medicine, Veterinärplatz 1, 1210 Vienna, Austria becoming faster and more efficient (Robinson and Sutherland 2002). Under these circumstances, one might expect that the harvest of arable crops in late summer causes a dramatic change in modern arable landscapes and may act as a stressor in vertebrates inhabiting the agricultural landscape.

One part of the physiological stress response is the activation of the hypothalamic-pituitary-adrenal (HPA) axis and subsequent secretion of glucocorticoids (GCs). The primary role of GCs is basic energy regulation, whereas increased secretion allows animals to mobilize stored energy to cope with stressful situations (Möstl and Palme 2002; Sheriff et al. 2011a). Chronic or long-term increases in GC levels can have detrimental effects on the organism, such as lower immune function, increased energy expenditure and potentially reduced reproduction and survival (Busch and Hayward 2009; Romero and Wingfield 2015). Nowadays, wellvalidated non-invasive methods are available to measure faecal glucocorticoid metabolites (fGCMs) and thus assess the impact of stressful situations on wildlife (Sheriff et al. 2011a; Palme 2019). Hence, we used fGCMs to evaluate whether harvesting of arable landscapes acts as a stressor 
and shows a negative effect on wildlife. As a typical inhabitant of arable landscapes, which numbers have been declining since the beginning of the twentieth century (Hackländer and Schai-Braun 2018) due to agricultural intensification (Smith et al. 2005), we used the European hare (Lepus europaeus) as a model species.

Whether the agricultural management system (conventional vs. organic) plays a part in buffering harvesting effects has not been addressed in studies yet (Marboutin and Aebischer 1996; Cimino and Lovari 2003; Roth et al. 2005; Schai-Braun et al. 2014; Shuford et al. 2015; Conkling et al. 2017). In the case of the study, organic farming was based on the management standards from Agrarmarkt Austria (AMA) implementing the council regulation 834/2007 (European Commission 2009). The associated renunciation of chemically synthetic pesticides and mineral nitrogen fertilizers has to be achieved, among others, by multiannual diverse crop rotation including legumes and other green manure crops and the choice of crop species (European Union 2007). Organic farming results in an increased habitat diversity in agricultural habitats (Norton et al. 2009). However, the increased diversity vary according to factors such as ethical beliefs of the farmer (Shepherd et al. 2003; Hole et al. 2005), respective landscape structures (Bengtsson et al. 2005), organic farming standards and economic realities of the marketplace (Hole et al. 2005). For this reason, the agricultural management system in general is probably unlikely to play a decisive role during harvest for wildlife species.

European hares use open ground with short vegetation as feeding areas within home ranges (Tapper and Barnes 1986; Mayer et al. 2018), whereas resting areas are chosen in landscapes providing shelter (Tapper and Barnes 1986; Neumann et al. 2011). During summer, arable crops provide mainly cover (Tapper and Barnes 1986; Rühe and Hohmann 2004; Neumann et al. 2011) and only seldom both forage and shelter (Reitz and Léonard 1994; Mayer et al. 2018). European hares feed selectively on different plant species (Reichlin et al. 2006) and select especially a diet rich in fat (Schai-Braun et al. 2015). Accordingly, harvest may alter the availability of habitats providing shelter, as well as the arrangement of required habitats within home ranges. Remaining habitats might be further away from each other leading to an increased energy expenditure (Swihart 1986) and predation risk. Moreover, suitable habitats could act as hot spots for European hares, resulting in potential risks of social stress (Lindlöf et al. 1978; Monaghan and Metcalfe 1985). As harvest neither influenced the home range size during resting periods nor the resting position in an arable landscape with enough non-farmed features $(<10 \%)$, such habitat types may buffer harvest effects (Schai-Braun et al. 2014).

The aim of this study was to investigate the influence of cereal harvest in an arable landscape on the stress level (measured by fGCMs) of European hares. Our hypotheses were that (1) cereal harvest increases fGCM levels in European hares; (2) the harvest-induced increase in fGCM levels results irrespective of the agricultural management system; (3) the reduction of shelter, measured by the change in vegetation density and height, increases fGCM levels; and (4) the availability of non-farmed features buffers the effect of cereal harvest on fGCM concentrations. We tested these hypotheses by collecting faecal pellets of European hares in an arable landscape over three periods - before, during and after harvestallowing for a comparison of fGCM concentrations.

\section{Materials and methods}

\section{Study area}

The study was conducted in two adjacent hunting grounds (Kronberg $48^{\circ} 25^{\prime} \mathrm{N}, 16^{\circ} 31^{\prime} \mathrm{E}$ and Traunfeld $48^{\circ} 27^{\prime} \mathrm{N}$, $16^{\circ} 31^{\prime} \mathrm{E}$ ) of 842 ha (Kronberg 390 ha, Traunfeld 452 ha) in Lower Austria during the year 2018. In the study area, arable land dominated (88\%), of which $24 \%$ was used for growing cereals. Stubble fields were covered by stubble from a previous crop, whereas bare ground was free from vegetation after tillage. For an overview of the habitat types in the study area, see Table 1 . The average field size was 1.85 ha $( \pm 0.1 \mathrm{SE})$. The field edge index, describing the length of the border between two different habitat types and therefore the diversity within an area, was $23.77 \mathrm{~km}$ per 100 ha (Pegel 1986). Organic farming was practised on $39 \%$ of the study area.

Predators such as corvids (e.g. Eurasian magpie Pica pica, carrion crow Corvus corone) or predatory mammals (e.g. stoat Mustela erminea, weasel Mustela nivalis, pine marten Martes martes, beech marten Martes foina, red fox Vulpes vulpes, badger Meles meles) were similarly controlled in both hunting grounds based on the legal foundation. Other birds of prey (e.g. common buzzard Buteo buteo, kestrel Falco tinnunculus, marsh harrier Circus aeruginosus), and storklike birds (order Ciconiiformes; e.g. grey heron Ardea cinerea, white stork Ciconia ciconia, great egret Ardea alba) were fully protected by law. The hunting season for hares started in both study areas on 1 October and ended 31 December in the year 2018.

Hare density was estimated each year in autumn and spring by spotlight counts (Langbein et al. 1999) from the local hunting association. Thereby, the complete agricultural land of the study area was illuminated with spotlights and hares counted during each spotlight count. On average 132 European hares per 100 ha $( \pm 33.9 \mathrm{SE})$ in Kronberg and 109 individuals per 100 ha $( \pm 0.7 \mathrm{SE})$ in Traunfeld were counted in the year 2018 .

\section{Habitat mapping}

We digitized all habitat types in the study area using plot maps and ArcGIS 14.4.1 (ESRI). Each plot was visited to determine 
Table 1 The 31 habitat types used to classify the study area's land use, a classification into seven categories and their area covered in percent before, during and after harvest in Lower Austria in the year 2018

\begin{tabular}{|c|c|c|c|c|c|}
\hline \multirow[t]{2}{*}{ Classification } & \multirow[t]{2}{*}{ Habitat type } & \multirow[t]{2}{*}{ Scientific name } & \multicolumn{3}{|l|}{ Area $(\%)$} \\
\hline & & & Before harvest & During harvest & After harvest \\
\hline \multirow[t]{5}{*}{ Cereals } & Winter wheat & Triticum aestivum $\mathrm{L}$. & 22.26 & 4.87 & - \\
\hline & Barley & Hordeum vulgare L. & 5.77 & 3.76 & - \\
\hline & Triticale & $x$ Triticosecale & 4.61 & 0.11 & - \\
\hline & Rye & Secale cereale $\mathrm{L}$. & 0.77 & 0.32 & - \\
\hline & Spelt & Triticum spelta L. & 0.45 & 0.45 & - \\
\hline \multirow[t]{15}{*}{ Field crops } & Corn & Zea mays L. & 7.64 & 7.64 & 7.64 \\
\hline & Mustard & Sinapis alba L. & 4.23 & 4.23 & 4.23 \\
\hline & Soybean & Glycine $\max \mathrm{M}$. & 3.44 & 3.44 & 3.44 \\
\hline & Sunflowers & Helianthus annuus L. & 3.38 & 3.38 & 3.38 \\
\hline & Oil pumpkins & Cucurbita pepo L. & 3.10 & 3.10 & 3.10 \\
\hline & Sugar beet & Beta vulgaris $\mathrm{L}$. & 2.94 & 2.94 & 2.94 \\
\hline & Flax & Linum usitatissimum L. & 2.89 & 2.89 & 2.89 \\
\hline & Rape & Brassica napus L. & 2.89 & - & - \\
\hline & Poppy & Papaver somniferum L. & 1.73 & 0.44 & - \\
\hline & Broad bean & Vicia faba $\mathrm{L}$. & 1.23 & 1.23 & 1.23 \\
\hline & Fennel & Foeniculum vulgare L. & 0.78 & 0.78 & 0.78 \\
\hline & Buckwheat & Fagopyrum esculentum & 0.62 & 0.62 & 0.62 \\
\hline & Peas & Pisum sativum L. & 0.47 & 0.24 & - \\
\hline & Safflower & Carthamus tinctorius L. & 0.20 & 0.20 & - \\
\hline & Millet & Panicum miliaceum L. & 0.15 & 0.15 & 0.15 \\
\hline \multirow[t]{4}{*}{ Grassland } & Fallow land & - & 7.78 & 7.78 & 7.78 \\
\hline & Lucerne & Medicago sativa $\mathrm{L}$. & 4.92 & 4.92 & 4.92 \\
\hline & Red clover & Trifolium pratense $\mathrm{L}$. & 0.76 & 0.76 & 0.76 \\
\hline & Field edge & - & 0.38 & 0.38 & 0.38 \\
\hline \multirow[t]{3}{*}{ Tree-covered habitat } & Forest & - & 7.56 & 7.56 & 7.56 \\
\hline & Hedge & - & 2.96 & 2.96 & 2.96 \\
\hline & Copses & - & 1.33 & 1.33 & 1.33 \\
\hline \multirow[t]{2}{*}{ Specialty crops } & Vine & Vitis vinifera & 3.99 & 3.99 & 3.99 \\
\hline & Pasture & - & 0.71 & 0.71 & 0.71 \\
\hline Bare ground & All bare ground & - & - & 5.30 & 26.61 \\
\hline Stubble fields & All stubble fields & - & - & 22.88 & 12.54 \\
\hline
\end{tabular}

the habitat type based on the main vegetation/usage type. Two adjacent plots with the same habitat type were considered to be one, while plots with different habitat types were considered to be separate. Habitat changes caused by harvest or subsequent tillage were noted daily during sampling periods.

We mapped the vegetation density as well as the vegetation height for each plot at three random points before each faecal pellet sampling period. The mean values of a given plot were used for the entire plot. The vegetation density was determined by the amount of soil that remained visible through the vegetation in a frame $(1 \mathrm{~m} \times 1 \mathrm{~m})$ (Gehlker 1977). The mean values were categorized as open $(<25 \%)$, sparse $(25-$ $49 \%)$, medium $(50-70 \%)$ and dense $(<75 \%)$ (Schai-Braun et al. 2014). The vegetation height was measured at the same points with a meter stick and classified as short $(<70 \mathrm{~mm})$, medium $(70-220 \mathrm{~mm})$ and tall $(>220 \mathrm{~mm})$ according to Smith et al. (2004).

\section{Faecal pellet collection}

Faecal pellets of European hares were collected in three periods from 12 June until 24 July 2018. "Before harvest" was defined as the time period immediately before cereal harvest started (12 June-17 June 2018). The second period "harvest" was during the winter wheat harvest (04 July-11 July 2018), whereas the "after harvest" period started 2 weeks later (18 July-24 July 2018). We collected all faecal pellets over a total transect length of $72 \mathrm{~km}$ along field boundaries and on tractor 
Table 2 Model 1 averaged coefficients of the covariates farming practice, collecting period, vegetation density and vegetation height for the response variable fGCM $(n=591)$

\begin{tabular}{llrrrr}
\hline & & Estimate & Std. error & Z value & $P$ value \\
\hline \multirow{3}{*}{ Collecting period } & Intercept & 16.741 & 1.050 & 15,923 & $<0.001$ \\
& Farming practice & -1.786 & 1.349 & 1322 & 0.186 \\
& Before harvest & -0.091 & 1.718 & 0,053 & 0.958 \\
Vegetation density & After harvest & 0.274 & 1.916 & 0,143 & 0.887 \\
& Dense/open & 1.678 & 2.025 & 0,827 & 0.408 \\
& Medium & -2.755 & 2.839 & 0,968 & 0.333 \\
& Medium/dense & -0.591 & 2.349 & 0,251 & 0.802 \\
& Open & -4.105 & 1.361 & 3.010 & 0.003 \\
& Medium/tall & -0.227 & 2.478 & 0,091 & 0.927 \\
& Short & -3.998 & 2.707 & 1474 & 0.140 \\
& Short/medium & -1.842 & 3.839 & 0,479 & 0.632 \\
& Short/tall & 0.345 & 2.793 & 0,123 & 0.902 \\
& Tall & -0.702 & 1.990 & 0,352 & 0.725 \\
\hline
\end{tabular}

lines in the crops. No hare movement due to discomfort caused by faecal pellet collection was noticed. Additionally, we examined areas with sparse vegetation and resting places of walked up hares near the transects for faecal pellets. Due to the increased locomotor activity of European hares during night and dawn (Schai-Braun et al. 2012), we started early in the morning (04:45 am) collecting fresh faecal pellets and stopped when identification of freshness was no longer possible $(10: 30 \mathrm{am})$ to avoid further bacterial degradation of fGCMs (Möstl et al. 1999; Thiel et al. 2005). All samples were transported in a styrofoam cooler box with six ice packs during field collection and later stored frozen at $-20{ }^{\circ} \mathrm{C}$ following the procedure of Rehnus et al. (2010). We stopped collecting during rainy weather conditions to prevent misidentification of freshness and washing out effects (Rehnus et al. 2009).

Each sample location was recorded with a GPS device (Garmin GPSMAP 60Cx) and consisted of a minimum of three pellets. The positional data were mapped in ArcGIS, and around each sample location, a circle with the size of 10 ha was drawn. We chose a 10 -ha circle because 24 -h home range sizes of European hares in comparable agricultural landscapes were recorded to be around 10 ha (Schai-Braun and Hackländer 2014). Subsequently, the habitat composition within the circle was evaluated on the assumption that it was used by the individual hare during the last $24 \mathrm{~h}$.

\section{Sample analysis}

To determine fGCM concentrations, we used a group-specific 11-oxoaetiocholanolone enzyme immunoassay (EIA), which measures 11,17-dioxoandrostanes (a group of cortisol metabolites). This EIA has proven suited for European hares (Teskey-Gerstl et al. 2000). Faecal pellets were dried at $75{ }^{\circ} \mathrm{C}$ for $5 \mathrm{~h}$. Afterwards, each sample was homogenized and $0.20 \mathrm{~g}( \pm 0.005 \mathrm{~g})$ mixed with $4.0 \mathrm{ml}$ methanol $(100 \%)$ and $1.0 \mathrm{ml}$ distilled water. Subsequently, the mixture was shaken for $30 \mathrm{~min}$ and centrifuged $(2500 \mathrm{x}$ g, GS-6KR, Beckman Coulter) for $10 \mathrm{~min}$ to determine the amount of fGCMs in the supernatant after a 1:10 dilution with assay buffer (Palme and Möstl 1997; Palme et al. 2013). Samples below the detection limit $(2.1 \mathrm{ng} / \mathrm{g}$ faeces $)$ were set at $2.1 \mathrm{ng} / \mathrm{g}$ faeces for the statistical analyses.
Table 3 Model 2 averaged coefficients of the covariates farming practice, collecting period and habitat types for the response variable fGCM $(n=591)$

\begin{tabular}{llrrrr}
\hline & Estimate & Std. error & Z value & $P$ value \\
\hline \multirow{3}{*}{ Collecting period } & Intercept & 15.593 & 2.237 & 6.965 & $<0.001$ \\
& Farming practice & -2.575 & 1.491 & 1.724 & 0.085 \\
& Before harvest & 0.186 & 2.487 & 0.075 & 0.941 \\
& During harvest & -1.162 & 1.967 & 0.590 & 0.555 \\
& Bare ground & -6.876 & 3.103 & 2.212 & 0.027 \\
& Stubble fields & 7.285 & 3.493 & 2.083 & 0.037 \\
& Specialty crops & 4.550 & 3.946 & 1.151 & 0.250 \\
& Grassland & 3.845 & 3.802 & 1.010 & 0.312 \\
& Cereals & 2.789 & 3.684 & 0.756 & 0.450 \\
& Field crops & 1.974 & 3.366 & 0.586 & 0.558 \\
& Tree covered & 1.715 & 4.101 & 0.417 & 0.676 \\
\hline
\end{tabular}




\section{Statistical analysis}

All statistical analyses were done with R 3.5.2 (R Development Core Team 2018). First, we grouped faecal samples according to the collecting period (before, during and after harvest). The Games-Howell test for post hoc testing was used to reveal differences between seasons (Peters 2018). Further analyses were conducted using linear mixed-effects models using the package lme4 (Bates et al. 2015). We tested the effects of the covariate vegetation height and density (model 1) as well as the covariate habitat types (model 2) on the response variable fGCM concentrations in two separate full models. This was because our sample size did not allow us to include all predictor variables together in one model. Thus, two models we computed to avoid overfitting. Both models included the collecting day as random factor in order to account for the different days of faecal sample collection within the three periods. Furthermore, the models included the explanatory variable collecting period (before harvest, harvest, after harvest) and type of farming practice (organic vs. conventional farming). Since there were never any significant interaction effects in our linear mixed-effects models $(p>0.1)$, we did not include interactions in our models. The full models were used to create a set of models with all combinations of the independent variables using the package MuMln (Bartoń 2019). $P$ values and estimates ( $\beta$ ) were extracted by model averaging (including all models with delta $\mathrm{AIC}<$

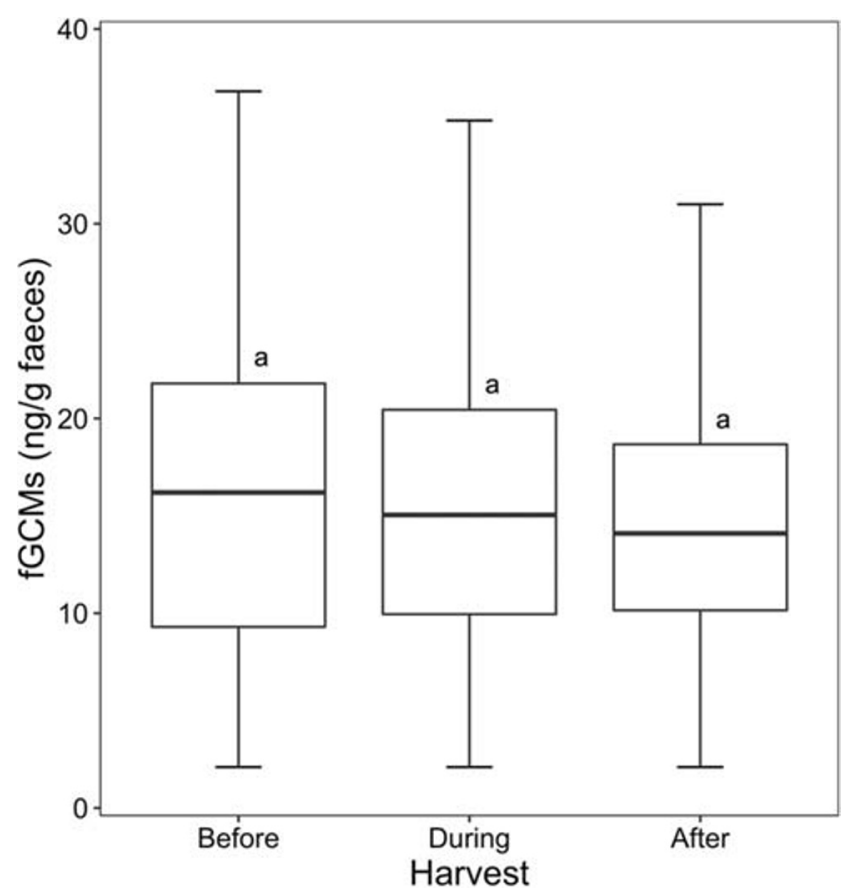

Fig. 1 fGCM concentrations of European hare faecal pellets collected before, during and after harvest in Lower Austria in the year 2018 ( $n=$ 591). Data are shown as medians with 25 th/75th and 10th/90th percentiles. Same letters indicate no significant differences between groups (post hoc: $P>0.1)$. See text for details on statistics
10). $P$ values less than 0.05 were considered as significant. The residuals of the full models were checked for normal distribution by viewing QQ plots and histograms. Additionally, residuals were plotted against fitted values to analyse homogeneity, censored data problems (Fox 2015) and goodness of fit of the models. Post hoc tests were computed with significant categorical variables using the Tukey's all-pair comparisons method in the package multcomp (Hothorn et al. 2008).

\section{Results}

We collected 591 faecal pellet samples on an overall transect length of $72 \mathrm{~km}$. Two hundred twelve samples were collected before, 212 during and 167 after harvest. Twenty-five faecal pellet samples were below the detection limit of fGCMs (before, 21; during, 2; after harvest, 2), but model diagnostics indicated no substantial censored data problems.

\section{The influence of cereal harvest and farming practice on faecal fGCM concentrations}

We found no significant differences in fGCM concentrations between collecting periods (Fig. 1, each $P>0.1$, Tables 2 and 3) or farming practice (Fig. 2, each $P>0.1$, Tables 2 and 3).

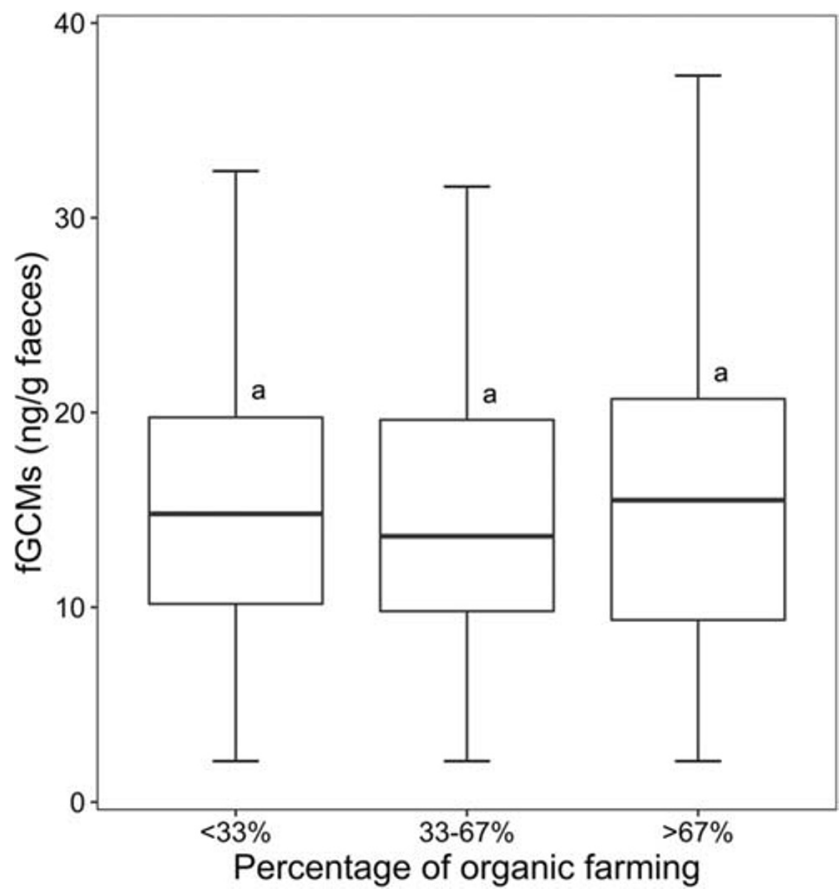

Fig. 2 fGCM concentrations of European hare faecal pellets according to organic vs. conventional framing collected in Lower Austria in the year $2018(n=591)$. Data are shown as medians with 25 th/75th and 10 th/90th percentiles. Same letters indicate no significant differences between groups (post hoc: $p>0.1$ ). See text for details on statistics 


\section{The influence of vegetation density and height on faecal fGCM concentrations}

Vegetation density as well as vegetation height changed during the study period (Table 4). Vegetation height had no effect on fGCM concentrations (each $P>0.1$, Table 3 ), whereas vegetation density had a significant influence on fGCM concentrations. The post hoc test revealed a significant difference between the categories open and dense (Table 5). Hence, faecal pellets found in plots with more than $50 \%$ of "open" vegetation density had significantly lower fGCM concentrations than faecal pellets found in plots with more than $50 \%$ of "dense" vegetation density (Fig. 3; $\beta=-4.014, p=0.021$ ).

\section{The influence of habitat types on faecal fGCM concentrations}

The habitat-type stubble fields positively affected fGCM concentrations (Fig. 4; $\beta=6.494, P=0.031$ ), whereas bare ground had a significant negative effect on fGCM concentrations in European hares (Fig. 5; $\beta=-7.153, P=0.013$ ). Thus, an increased proportion of stubble fields in the plots augmented fGCM concentrations, while an increased proportion of bare ground in the plots lowered fGCM concentrations. All other habitat types had no significant impact on the adrenocortical activity in European hares (each $P>0.1$, Table 3).

\section{Discussion}

In our study, we used the non-invasive approach of measuring fGCM concentrations in order to detect an influence of anthropogenic-induced habitat changes. Faecal GCMs appear to be a reliable indicator of the physiological stress response, as well as the most practical and least invasive (Sheriff et al. 2011b). However, there are a number of potential confounding factors. Season, diurnal rhythm, changes in diet, reproductive state, individual and sex can all influence concentrations of fGCMs (Dantzer et al. 2014; Palme 2019). These possible
Table 5 Post hoc test results (estimates $\beta$ und $p$-values) of the grouped vegetation densities for the covariate fGCM concentrations using the Tukey's all-pair comparisons method

\begin{tabular}{lccc}
\hline & Estimate & Std. error & P value \\
\hline Open vs. dense & -4.014 & 1.344 & 0.021 \\
Open vs. dense/open & -5.837 & 2.245 & 0.063 \\
Open vs. medium & -1.475 & 3.020 & 0.987 \\
Open vs. medium/dense & -3.494 & 2.590 & 0.635 \\
Medium vs. dense & -2.539 & 2.823 & 0.886 \\
Medium vs. dense/open & -4.362 & 3.386 & 0.674 \\
Medium/dense vs. dense & -0.520 & 2.347 & 0.999 \\
Medium/dense vs. dense/open & -2.343 & 2.988 & 0.927 \\
Medium/dense vs. medium & 2.019 & 3.601 & 0.978 \\
Dense/open vs. dense & 1.823 & 2.016 & 0.884 \\
\hline
\end{tabular}

risks were minimized as all faecal pellets were collected during one season, within a short time period and at nearly the same time of the day (Palme 2019). Possible confounding effects might have resulted from the individual and sex since we collected "anonymously" (Rehnus and Palme 2017). Hence, we cautiously interpret the result as a first indication of the impact that harvest may have on the stress level. Further studies should show whether the individual and sex play a crucial role in this context. The proportion of non-detects was higher before $(9.9 \%)$ than during $(0.9 \%)$ or after harvest $(1.2 \%)$. Our maximum fGCM concentrations was $65.6 \mathrm{ng} / \mathrm{g}$ faeces, and we interpret that values of $\leq 2.1 \mathrm{ng} / \mathrm{g}$ faeces (lower than the detection limit of the EIA) indicate no stress. Hence, we assume no mayor influence of the unequal distribution of non-detects between the different periods on our results.

\section{Influence of cereal harvest on fGCM concentrations}

A meta-analysis, including mammals, birds, reptiles and amphibians, has shown that anthropogenic-induced disturbances including habitat modifications and machines were associated
Table 4 Relative frequency of vegetation height and density in the study area before, during and after harvest in Lower Austria in the year 2018

\begin{tabular}{llllll}
\hline & Category & Classification & \multicolumn{2}{l}{ Area $(\%)$} \\
\cline { 3 - 5 } & & & Before harvest & During harvest & After harvest \\
\hline \multirow{2}{*}{ Vegetation height } & Short & $<70 \mathrm{~mm}$ & 2.81 & 7.72 & 29.03 \\
& Medium & $70-220 \mathrm{~mm}$ & 2.87 & 23.96 & 14.82 \\
& Tall & $>220 \mathrm{~mm}$ & 94.31 & 68.32 & 56.16 \\
Vegetation density & Open & $<25 \%$ & 5.27 & 33.08 & 46.50 \\
& Sparse & $25-49 \%$ & 9.00 & 1.76 & 0.27 \\
& Medium & $50-75 \%$ & 21.64 & 16.83 & 14.38 \\
& Dense & $>75 \%$ & 64.09 & 48.32 & 38.85 \\
\hline
\end{tabular}




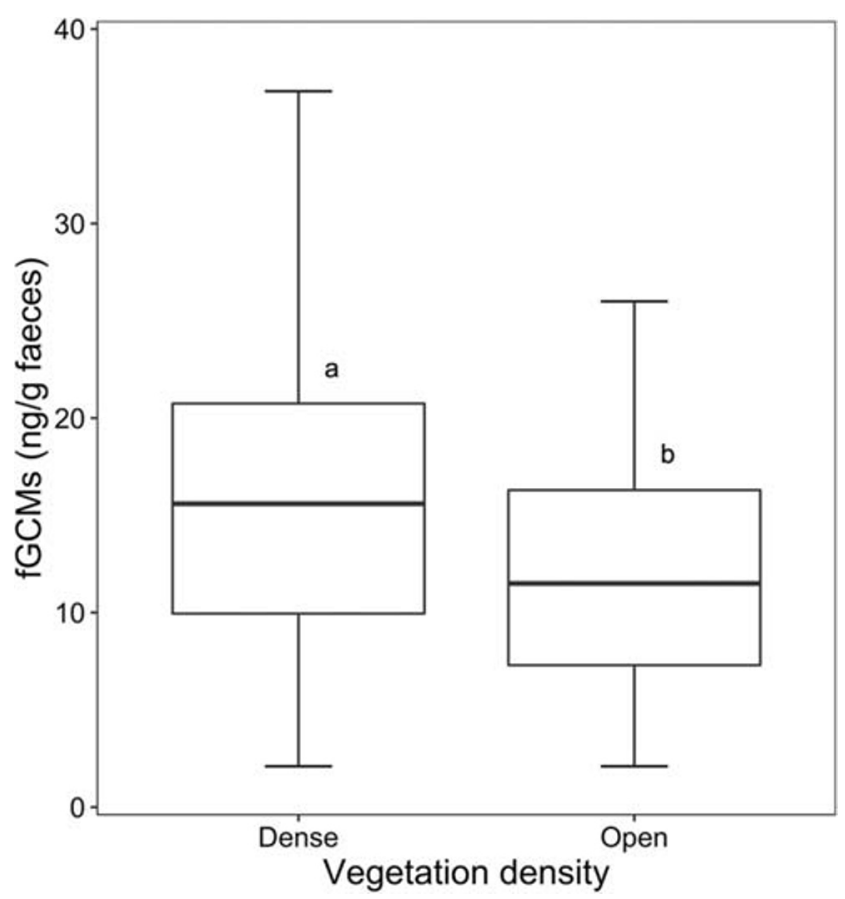

Fig. 3 fGCM concentrations of European hare faecal pellets according to vegetation density collected in Lower Austria in the year $2018(n=591)$. Only the dense $(>75 \%)$ and open $(<25 \%)$ categories are shown. Data are shown as medians with 25 th $/ 75$ th and 10 th/90th percentiles. Different letters indicate significant differences between groups. See text for details on statistics

consistently with increased fGCM concentrations (Dantzer et al. 2014). In contrast, we found no significant differences

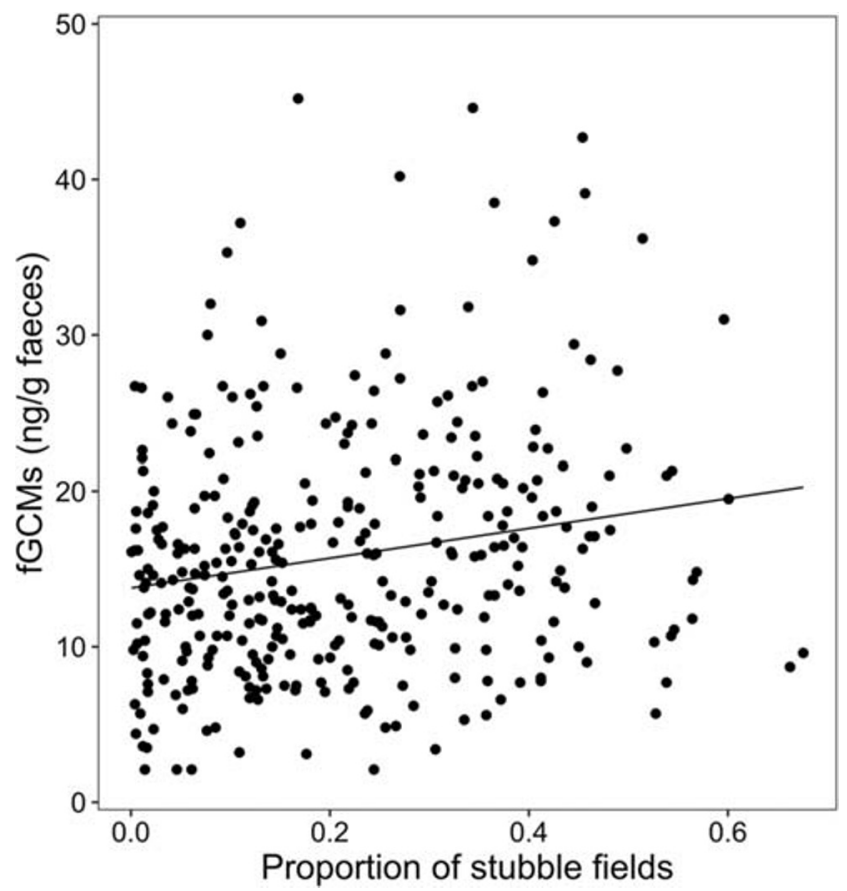

Fig. 4 The influence of the proportion of stubble fields within the 10-ha circular plots on fGCM concentrations of European hare faecal pellets collected in Lower Austria in the year $2018(n=591)$. The regression line is statistically significant. See text for details on statistics in fGCM concentrations between three faeces collecting periods, including cereal harvest.

An effect of harvesting arable crops on fGCM concentrations is assumed when required habitat requisites disappear, and such a change leads to a lack of suitable habitats. In 2018, cereal harvest started early but was repeatedly interrupted by unsuitable weather conditions. Therefore, only $28 \%$ of the study area was affected by habitat changes during the "harvest" sampling period. The average field size, or even better the field edge index, determines the habitat diversity within a home range (Pegel 1986). As the average field size was low $(1.84 \mathrm{ha})$ and the field edge index was large $(23.77 \mathrm{~km}$ per 100 ha), we suggest that European hares could use plenty of different habitats unaffected by harvest within their home range. Non-farmed features, such as hedges, fallow land, and set-asides preferred by European hares (Smith et al. 2004; Pépin and Angibault 2007; Cardarelli et al. 2011; Vidus-Rosin et al. 2011; Schai-Braun et al. 2013), accounted for $11 \%$ of the agricultural landscape. Additionally, positively selected food plants such as lucerne (Medicago sativa $\mathrm{L}$ ), red clover (Trifolium pratense L.) and soybean (Glycine max M.) (Reichlin et al. 2006) accounted for 9\% of the study area. This assumption is in line with the findings of Hunninck et al. (2020) that human disturbance including agriculture and farming practices were only found to be a secondary stressor compared to forage availability in impala (Aepyceros melampus). Furthermore, habitat complexity seems to be an important factor by explaining differences in fGCM levels in another

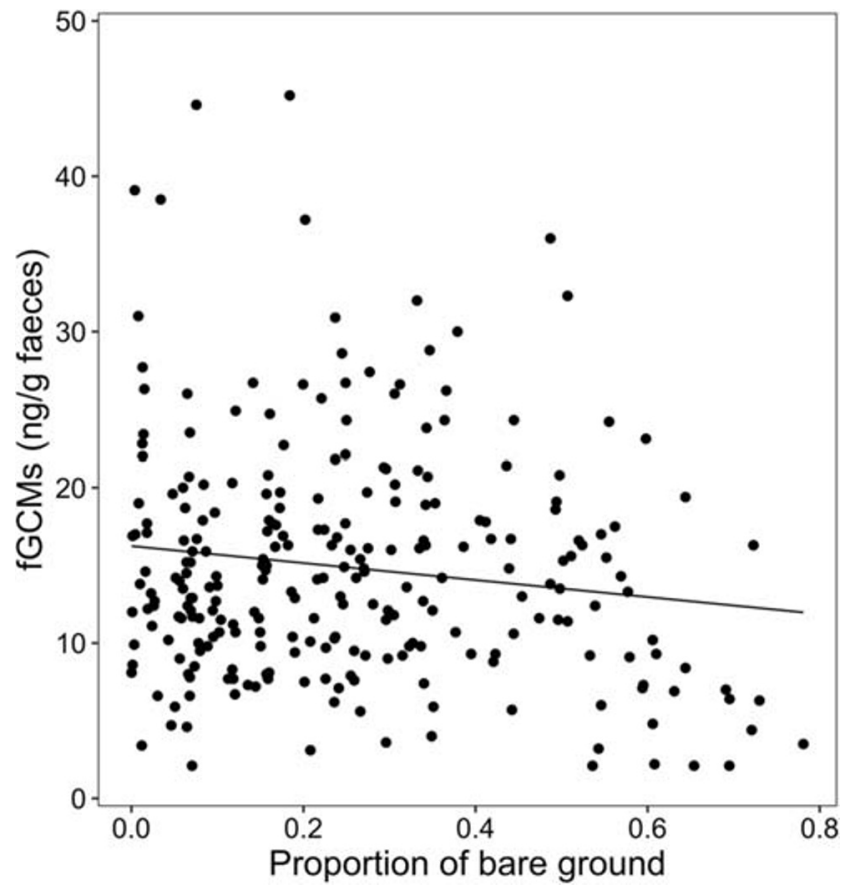

Fig. 5 The influence of the proportion of bare ground within the 10-ha circular plots on fGCM concentrations of European hare faecal pellets collected in Lower Austria in the year $2018(n=591)$. The regression line is statistically significant. See text for details on statistics 
small mammal the common vole (Microtus arvalis, NavarroCastilla et al. 2013). Hence, we suggest that the providing of unaffected habitats could buffer an effect of agricultural practices due to harvesting in the European hare.

\section{Influence of farming practice on fGCM concentrations}

As predicted, the agricultural management system had no significant effect on fGCM concentrations of European hares during harvest. The conventionally managed land of the study area had a high proportion of non-farmed features, such as setasides (organic $8.3 \%$, conventional $7 \%$ ) and hedges (organic $1.7 \%$, conventional $3.2 \%$ ), as well as small average field size (organic 1.62, conventional $1.8 \mathrm{ha}$ ) and a high field edge index (organic $25.12 \mathrm{~km}$, conventional $24.65 \mathrm{~km}$ per $100 \mathrm{ha}$ ), and was, thus, comparable to the organically farmed study area. This suggests that a diverse small-scale landscape is more likely to limit the effect of cereal harvest on fGCM concentrations of European hares than the farming system. This is in line with the expectation of Bengtsson et al. (2005) that organic farming has a positive effect in intensively managed agricultural landscapes, but not in diverse small-scale landscapes.

\section{Influence of vegetation density and height on fGCM concentrations}

Changes in predation risk were associated with impacts on the stress levels within the genus Lepus (Lepus americanus; Sheriff et al. 2011b). In contrary to this, harvest-induced reduction of vegetation density led to lower fGCM concentrations in our study. This might be explained by Marboutin and Aebischer (1996) reporting that active European hares decreased time spent scanning after harvest because the landscape was easier to overview. Furthermore, European hares are morphologically well adapted to open landscapes due to their origin in the Eurasian steppe (Hackländer and SchaiBraun 2018). Cereal harvest increased the amount of open vegetation densities from 5 up to $47 \%$ in the study area but dense and medium vegetation densities still account for $53 \%$. We assume that in a small-scale landscape, enough suitable habitats for shelter are provided after harvest for resting hares and rather more areas become accessible again for hares during activity (Rühe 1999; Mayer et al. 2018).

Vegetation height is often used to determine habitat utilization in European hares (Rühe 1999; Smith et al. 2004; Mayer et al. 2018). However, we found no influence of vegetation height on fGCM concentrations. This suggests that vegetation density should be considered more closely as an essential factor for active and resting European hares in future hare studies. This is in line with Neumann et al. (2011) reporting that cover value is especially important for shelter selection in resting European hares.
Influence of habitat types on fGCM concentrations

Higher fGCM concentrations due to stubble fields are difficult to interpret. Habitat degradation is associated with increased adrenocortical activity in a variety of wildlife species (Marra and Holberton 1998; Homan et al. 2003; Martínez-Mota et al. 2007; Jachowski et al. 2012; Johnstone et al. 2012; Rimbach et al. 2013; Balestri et al. 2014). However, previous studies on European hares indicated a positive habitat selection of stubble fields (Ahrens 1990; Lewandowski and Nowakowski 1993; Reitz and Léonard 1994) and an increased use of already cut cereal fields (Schai-Braun et al. 2014). Since stubble fields only occur through harvesting processes, increased fGCM level associated with stubble fields is not congruent with the findings that harvest did not alter the fGCM levels. Future studies have to show in which context this result should be seen.

Lower fGCM concentrations due to bare ground can be explained by the preference of such habitats by European hares (Schai-Braun et al. 2013). The dug-over fallen grains started to shoot and provided an additional food source due to rainy weather conditions (Pfister 1984; Späth 1989; Chapuis 1990).

Acknowledgements We thank the hunting societies of Traunfeld and Kronberg for cooperation, especially Robert and Herbert Schütz. Furthermore, we would like to thank the technicians of the Experimental Endocrinology laboratory (Department of Biomedical Sciences, University of Veterinary Medicine, Vienna) for excellent work.

Funding Open access funding provided by University of Natural Resources and Life Sciences Vienna (BOKU). This study was financed by the Verein Grünes Kreuz.

Open Access This article is licensed under a Creative Commons Attribution 4.0 International License, which permits use, sharing, adaptation, distribution and reproduction in any medium or format, as long as you give appropriate credit to the original author(s) and the source, provide a link to the Creative Commons licence, and indicate if changes were made. The images or other third party material in this article are included in the article's Creative Commons licence, unless indicated otherwise in a credit line to the material. If material is not included in the article's Creative Commons licence and your intended use is not permitted by statutory regulation or exceeds the permitted use, you will need to obtain permission directly from the copyright holder. To view a copy of this licence, visit http://creativecommons.org/licenses/by/4.0/.

\section{References}

Ahrens A (1990) Zur Verteilung von Feldhasen bei der Besatzermittlung auf der landwirtschaftlichen Nutzfläche. Beiträge zur Jagd- und Wildtierforschung 17:122-130

Balestri M, Barresi M, Campera M, Serra V, Ramanamanjato JB, Heistermann M, Donati G (2014) Habitat degradation and seasonality affect physiological stress levels of Eulemur collaris in littoral forest fragments. PLoS One 9:e107698 
Bartoń K (2019) Multi-model inference. cran.r-project.org. https://cran.rproject.org/web/packages/MuMIn/MuMIn.pdf. Accessed 04 Aug 2019

Bates D, Mächler M, Bolker BM, Walker SC (2015) Fitting linear mixedeffects models using lme4. J Stat Softw 67:1-48

Bengtsson J, Ahnström J, Weibull AC (2005) The effects of organic agriculture on biodiversity and abundance: a meta-analysis. J Appl Ecol 42:261-269

Benton TG, Vickery JA, Wilson JD (2003) Farmland biodiversity: is habitat heterogeneity the key? Trends Ecol Evol 18:182-180

Busch DS, Hayward LS (2009) Stress in a conservation context: a discussion of glucocorticoid actions and how levels change with conservation-relevant variables. Biol Conserv 142:28442853

Cardarelli E, Meriggi A, Brangi A, Vidus-Rosin A (2011) Effects of arboriculture stands on European hare Lepus europaeus spring habitat use in an agricultural area of northern Italy. Acta Theriol 56: 229-238

Casas F, Benítez-López A, Tarjuelo R, Barja I, Viñuela J, García J, Morales MB, Mougeot F (2016) Changes in behaviour and faecal glucocorticoid levels in response to increased human activities during weekends in the pin-tailed sandgrouse. Sci Nat 103:91

Chapuis JL (1990) Comparison of the diets of two sympatric lagomorphs, Lepus europaeus (Pallas) and Oryctolagus cuniculus (L.) in an agroecosystem of the Ile-de-France. Zeitschrift für Säugetierkunde $55: 176-185$

Cimino L, Lovari S (2003) The effects of food or cover removal on spacing patterns and habitat use in roe deer (Capreolus capreolus). J Zool 261:299-305

Conkling TJ, Belant JL, DeVault TL, Martin JA (2017) Effects of crop type and harvest on nest survival and productivity of dickcissels in semi-natural grasslands. Agric Ecosyst Environ 240:224-232

Dantzer B, Fletcher QE, Boonstra R, Sheriff MJ (2014) Measures of physiological stress: a transparent or opaque window into the status, management and conservation of species? Conserv Physiol 2: cou023

European Commission (2009) Staatliche Beihilfe N 589/2008 Österreich Qualitätsprogramme und das AMA-Biozeichen und das AMA-Gütesiegel. European Commission. https://ec.europa.eu/ competition/state_aid/cases/228505/228505_928357_50_2.pdf. Accessed 06 Jul 2020

European Union (2007) Council regulation (EC) no 834/2007 of 28 June 2007 on organic production and labelling of organic products and repealing regulation (EEC) no 2092/91. Eur-lex Access to European Union law. http://data.europa.eu/eli/reg/2007/834/oj. Accessed 06 Jul 2020

Fox GA (2015) What you don't know can hurt you: censored and truncated data in ecological research. In: Fox GA, Negrete-Yankelevich S, Sosa VJ (eds) Ecological Statistics. Oxford Univ Press, Oxford, pp 230-257

Gehlker H (1977) Eine Hilfstafel zur Schätzung von Deckungsgrad und Artmächtigkeit. Mitteilungen der Floristisch-Soziologischen Arbeitsgemeinschaft N.F. 19 / 20:427-429

Hackländer K, Schai-Braun SC (2018) Lepus europaeus Pallas, 1778 European hare. In: Smith AT, Johnston CH, Alves PC, Hackländer K (eds) Lagomorphs: pikas, rabbits, and hares. John Hopkins University Press, Baltimore, pp 187-190

Hole DG, Perkins AJ, Wilson JD, Alexander IH, Grice PV, Evans AD (2005) Does organic farming benefit biodiversity? Biol Conserv 122:113-130

Homan RN, Regosin JV, Rodrigues DM, Reed JM, Windmiller BS, Romero M (2003) Impacts of varying habitat quality on the physiological stress of spotted salamanders (Ambystoma maculatum). Anim Conserv 6:11-18

Hothorn T, Bretz F, Westfall P (2008) Simultaneous inference in general parametric models. Biom J 50:346-363
Hunninck L, May R, Jackson CR, Palme R, Røskaft E, Sheriff MJ (2020) Consequences of climate-induced vegetation changes exceed those of human disturbance for wild impala in the Serengeti ecosystem. Conserv Physiol 8:coz117

Jachowski DS, Slotow R, Millspaugh JJ (2012) Physiological stress and refuge behavior by African elephants. PLoS One 7:e31818

Johnstone CP, Lill A, Reina RD (2012) Does habitat fragmentation cause stress in the agile antechinus? An haematological approach. J Comp Physiol B 182:139-155

Langbein J, Hutchings MR, Harris S, Stoate C, Tapper SC, Wray S (1999) Techniques for assessing the abundance of brown hares Lepus europaeus. Mammal Rev 29:93-116

Lewandowski K, Nowakowski JJ (1993) Spatial distribution of brown hare Lepus europaeus population in habitats of various types of agriculture. Acta Theriol 38:435-442

Lindlöf B, Pehrson Å, Johansson A (1978) Summer food preference by penned mountain hares in relation to nutrient content. J Wildl Manag 42:928-932

Lunde ET, Bech C, Fyumagwa RD, Jackson CR, Røskaft E (2016) Assessing the effect of roads on impala (Aepyceros melampus) stress levels using faecal glucocorticoid metabolites. Afr J Ecol 54:434 441

Marboutin E, Aebischer NJ (1996) Does harvesting arable crops influence the behaviour of the European hare Lepus europaeus? Wildl Biol 2:83-91

Marra PP, Holberton RL (1998) Corticosterone levels as indicators of habitat quality: effects of habitat segregation in a migratory bird during the non-breeding season. Oecologia 116:284-292

Martínez-Mota R, Valdespino C, Sánchez-Ramos MA, Serio-Silva JC (2007) Effects of forest fragmentation on the physiological stress response of black howler monkeys. Anim Conserv 10:374-379

Mayer M, Ullmann W, Sunde P, Fischer C, Blaum N (2018) Habitat selection by the European hare in arable landscapes: the importance of small-scale habitat structure for conservation. Ecol Evol 8: 11619-11633

Monaghan P, Metcalfe NB (1985) Group foraging in wild brown hares: effects of resource distribution and social status. Anim Behav 33: 993-999

Möstl E, Palme R (2002) Hormones as indicators of stress. Domest Anim Endocrinol 23:67-74

Möstl E, Messmann S, Bagu E, Robia C, Palme R (1999) Measurement of glucocorticoid metabolite concentrations in faeces of domestic livestock. J Veterinary Med Ser A 46:621-631

Navarro-Castilla Á, Barja I, Olea PP, Piñeiro A, Mateo-Tomás P, Silván G, Illera JC (2013) Are degraded habitats from agricultural crops associated with elevated faecal glucocorticoids in a wild population of common vole (Microtus arvalis)? Mamm Biol 79:36-43

Neumann F, Schai-Braun SC, Weber D, Amrhein V (2011) European hares select resting places for providing cover. Hystrix 22:291-299

Norton L, Johnson P, Joys A, Stuart R, Chamberlain D, Feber R, Firbank L, Manley W, Wolfe M, Hart B, Mathews F, Macdonald D, Fuller $\mathrm{RJ}$ (2009) Consequences of organic and non-organic farming practices for field, farm and landscape complexity. Agric Ecosyst Environ 129:221-227

Palme R (2019) Non-invasive measurement of glucocorticoids: advances and problems. Physiol Behav 199:229-243

Palme R, Möstl E (1997) Measurement of cortisol metabolites in faeces of sheep as a parameter of cortisol concentration in blood. Int J Mamm Biol 62:192-197

Palme R, Touma C, Arias N, Dominchin MF, Lepschy M (2013) Steroid extraction: get the best out of faecal samples. Wien Tierärztl Mon 100:238-246

Pegel M (1986) Der Feldhase (Lepus europaeus Pallas) im Beziehungsgefüge seiner Um- und Mitweltfaktoren. Ferdinand Enke Verlag, Stuttgart 
Pépin D, Angibault JM (2007) Selection of resting sites by the European hare as related to habitat characteristics during agricultural changes. Eur J Wildl Res 53:183-189

Peters G (2018) Quantitative analysis made accessible. cran.r-project.org. https://cran.r-project.org/web/packages/userfriendlyscience/ userfriendlyscience.pdf. Accessed 04 Aug 2019

Pfister HP (1984) Raum-zeitliche Verteilungsmuster von Feldhasen (Lepus europaeus Pallas) in einem Ackerbaugebiet des schweizerischen Mittellandes. Dissertation, Universität Zürich

R Development Core Team (2018) R: a language and environment for statistical computing. www.R-project.org. Accessed 20 Oct 2018

Rehnus M, Palme R (2017) How genetic data improve the interpretation of results of faecal glucocorticoid metabolite measurements in a free-living population. PLoS One 12:e0183718

Rehnus M, Hackländer K, Palme R (2009) A non-invasive method for measuring glucocorticoid metabolites (GCM) in mountain hares (Lepus timidus). Eur J Wildl Res 55:615-620

Rehnus M, Palme R, Filli F, Hackländer K (2010) Seasonal glucocorticoid secretion in mountain hares (Lepus timidus). Mammalia 74: $347-350$

Rehnus M, Wehrle M, Palme R (2014) Mountain hares Lepus timidus and tourism: stress events and reactions. J Appl Ecol 51:6-12

Reichlin T, Klansek E, Hackländer K (2006) Diet selection by hares (Lepus europaeus) in arable land and its implications for habitat management. Eur J Wildl Res 52:109-118

Reitz F, Léonard Y (1994) Characteristics of European hare Lepus europaeus use of space in a French agricultural region of intensive farming. Acta Theriol 39:143-157

Rimbach R, Link A, Heistermann M, Gómez-Posada C, Galvis N, Heymann EW (2013) Effects of logging, hunting, and forest fragment size on physiological stress levels of two sympatric ateline primates in Colombia. Conserv Physiol 1:1-11

Robinson RA, Sutherland WJ (2002) Post-war changes in arable farming and biodiversity in Great Britain. J Appl Ecol 39:157-176

Romero LM, Wingfield JC (2015) Tempests, predators, poxes, and people: stress in wild animals and how they cope. Oxford University Press, New York

Roth A, Sample D, Ribic C, Paine L, Undersander D, Bartelt G (2005) Grassland bird response to harvesting switchgrass as a biomass energy crop. Biomass Bioenergy 28:490-498

Rühe F (1999) Effect of stand structures in arable crops on brown hare (Lepus europaeus) distribution. Gibier Faune Sauvage 16:317-337

Rühe F, Hohmann U (2004) Seasonal locomotion and home-range characteristics of European hares (Lepus europaeus) in an arable region in central Germany. Eur J Wildl Res 50:101-111

Schai-Braun SC, Hackländer K (2014) Home range use by the European hare (Lepus europaeus) in a structurally diverse agricultural landscape analysed at a fine temporal scale. Acta Theriol 59:277-287

Schai-Braun SC, Rödel HG, Hackländer K (2012) The influence of daylight regime on diurnal locomotor activity patterns of the European hare (Lepus europaeus) during summer. Mamm Biol 77:434-440

Schai-Braun SC, Weber D, Hackländer K (2013) Spring and autumn habitat preferences of active European hares (Lepus europaeus) in an agricultural area with low hare density. Eur J Wildl Res 59:387397
Schai-Braun SC, Peneder S, Frey-Roos F, Hackländer K (2014) The influence of cereal harvest on the home-range use of the European hare (Lepus europaeus). Mammalia 78:497-506

Schai-Braun SC, Reichlin TS, Ruf T, Klansek E, Tataruch F, Arnold W, Hackländer K (2015) The European hare (Lepus europaeus): a picky herbivore searching for plant parts rich in fat. PLoS One 10: e0134278

Shepherd M, Pearce B, Cormack B, Philipps L, Cuttle S, Bhogal A, Costigan P, Unwin R (2003) An assessment of the environmental impacts of organic farming. https:/www.researchgate.net/ publication/237799525_An_assessment_of the environmental impacts_of_organic_farming, Accessed 04 Aug 2019

Sheriff MJ, Dantzer B, Delehanty B, Palme R, Boonstra R (2011a) Measuring stress in wildlife: techniques for quantifying glucocorticoids. Oecologia 166:869-887

Sheriff MJ, Krebs CJ, Boonstra R (2011b) From process to pattern: how fluctuating predation risk impacts the stress axis of snowshoe hares during the 10-year cycle. Oecologia 166:593-605

Shuford D, Reiter M, Strum K, Gilbert M, Hickey C, Golet G (2015) The benefits of crops and field management practices to wintering waterbirds in the Sacramento-San Joaquin River Delta of California. Renew Agric Food Syst 31:495-506

Smith RK, Jennings NV, Robinson A, Harris S (2004) Conservation of European hares Lepus europaeus in Britain: is increasing habitat heterogeneity in farmland the answer? J Appl Ecol 41:1092-1102

Smith RK, Jennings NV, Harris S (2005) A quantitative analysis of the abundance and demography of European hares Lepus europaeus in relation to habitat type, intensity of agriculture and climate. Mammal Rev 35:1-24

Späth V (1989) Untersuchungen zur Populationsökologie des Feldhasen (Lepus europaeus) in der Oberrheinebene. Selbstverlag des Instituts für Forstzoologie, Freiburg im Breisgau

Swihart RK (1986) Home range - body mass allometry in rabbits and hares (Leporidae). Acta Theriol 31:139-148

Tapper SC, Barnes RF (1986) Influence of farming practice on the ecology of the brown hare (Lepus europaeus). J Appl Ecol 23:39-52

Teskey-Gerstl A, Bamberg E, Steineck T, Palme R (2000) Excretion of corticosteroids in urine and faeces of hares (Lepus europaeus). J Comp Physiol B 170:163-168

Thiel D, Jenni-Eiermann S, Palme R (2005) Measuring corticosterone metabolites in droppings of capercaillies (Tetrao urogallus). Ann N Y Acad Sci 1046:96-108

Thiel D, Jenni-Eiermann S, Braunisch V, Palme R, Jenni L (2008) Ski tourism affects habitat use and evokes a physiological stress response in capercaillie Tetrao urogallus: a new methodological approach. J Appl Ecol 45:845-853

Vidus-Rosin A, Meriggi A, Cardarelli E, Serrano-Perez S, Mariani M, Corradelli C, Barba A (2011) Habitat overlap between sympatric European hares (Lepus europaeus) and Eastern cottontails (Sylvilagus floridanus) in northern Italy. Acta Theriol 56:53-61

Zbyryt A, Bubnicki JW, Kuijper DPJ, Dehnhard M, Churski M, Schmidt K (2018) Do wild ungulates experience higher stress with humans than with large carnivores? Behav Ecol 29:19-30

Publisher's note Springer Nature remains neutral with regard to jurisdictional claims in published maps and institutional affiliations. 